\title{
Efficacy and Prognosis of First-Line EGFR-Tyrosine Kinase Inhibitor Treatment in Older Adults Including Poor Performance Status Patients with EGFR-Mutated Non-Small-Cell Lung Cancer
}

\author{
Cheng-Yu Chang (iD) ${ }^{1, *}$ \\ Chung-Yu Chen (D) $^{2,3, *}$ \\ Shih-Chieh Chang ${ }^{4-6, *}$ \\ Yi-Chun Lai ${ }^{4,5}$ \\ Yu-Feng Wei id ${ }^{7-9}$ \\ 'Division of Chest Medicine, Department \\ of Internal Medicine, Far Eastern \\ Memorial Hospital, New Taipei City, \\ Taiwan; ${ }^{2}$ Department of Internal \\ Medicine, National Taiwan University \\ Hospital Yunlin Branch, Yunlin County, \\ Taiwan; ${ }^{3}$ College of Medicine, National \\ Taiwan University, Taipei, Taiwan; \\ ${ }^{4}$ Division of Chest Medicine, Department \\ of Internal Medicine, National Yang-Ming \\ Chiao Tung University Hospital, Yi-Lan, \\ Taiwan; ${ }^{5}$ Faculty of Medicine, College of \\ Medicine, National Yang-Ming Chiao Tung \\ University, Taipei, Taiwan; ${ }^{6}$ Department \\ of Critical Care Medicine, National Yang- \\ Ming Chiao Tung University Hospital, Yi- \\ Lan, Taiwan; ${ }^{7}$ School of Medicine for \\ International Students, College of \\ Medicine, I-Shou University, Kaohsiung, \\ Taiwan; ${ }^{8}$ Department of Internal \\ Medicine, E-Da Cancer Hospital, \\ Kaohsiung, Taiwan; ${ }^{9}$ Institute of \\ Biotechnology and Chemical Engineering, \\ I-Shou University, Kaohsiung, Taiwan
}

*These authors contributed equally to this work

Correspondence: Yu-Feng Wei

Department of Internal Medicine, E-Da Cancer Hospital, Kaohsiung, Taiwan, No.

21, Yida Road, Jiao-su Village, Yan-chao

District, Kaohsiung, 824, Taiwan

Tel +886-7-6I500I I

Fax +886-7-6150927

Email yufeng528@gmail.com
Introduction: Epidermal growth factor receptor tyrosine kinase inhibitors (EGFR-TKIs) are standard first-line treatments for advanced EGFR-mutated non-small-cell lung cancer (NSCLC) patients. The efficacy of EGFR-TKIs in older patients including poor Eastern Cooperative Oncology Group (ECOG) performance status (PS) is seldom investigated.

Methods: We enrolled patients 65 years or older with EGFR-mutated Stage IIIB-IV NSCLC and evaluated the efficacy and prognosis of first-line EGFR-TKI treatment. Clinical and demographic characteristics were reviewed and analyzed, including age, sex, PS, smoking history, EGFR mutation type, treatment regimen, progression-free survival (PFS), and overall survival (OS).

Results: From January 2015 to December 2019, a total of 237 patients were included, 205 of whom were eligible for efficacy and outcome analyses. Among them, 91 (44.4\%) were categorized as poor PS (2-4). Compared with patients categorized as good PS (0-1), those with poor PS were older ( 79 versus 75 years), had a higher proportion of brain metastases (41.8\% versus $25.4 \%$ ), more comorbidities (74.7\% versus $54.4 \%$ ), and more likely to be treated with first-generation TKIs (74.7\% versus $57.0 \%)$. The PFS and OS were 17.1 and 26.7 months respectively in patients with good PS and 12.7 and 18.2 months in those with poor PS (both $\mathrm{p}<0.001$ ). In the multivariate analysis, good PS, $<3$ metastatic sites, and firstline treatment with afatinib compared with erlotinib and gefitinib were associated with longer PFS. A relatively younger age, good PS, $<3$ metastatic sites, and no brain metastasis at diagnosis were associated with better OS.

Conclusion: In older patients with EGFR-mutated NSCLC and receive EGFR-TKI treatment, a good PS and $<3$ metastatic sites at diagnosis were associated with a longer PFS and OS. In addition, afatinib as first-line treatment was associated with a longer PFS whereas a relatively younger age and no brain metastasis at diagnosis were associated with better OS. Keywords: older adults, epidermal growth factor receptor tyrosine kinase inhibitor, nonsmall-cell lung cancer, performance status

\section{Introduction}

Lung cancer is the leading cause of cancer deaths worldwide, including in Taiwan. ${ }^{1}$ Non-small cell lung cancer (NSCLC) accounts for $85 \%$ of all lung cancer cases, and more than $70 \%$ of NSCLC patients present with locally advanced or metastatic disease (Stage III or IV) at initial diagnosis. ${ }^{2}$ 
In Taiwan, approximately two-thirds of all lung cancer patients are older than 65 years at the time of diagnosis and have significantly inferior overall survival (OS) than those with age $<65$ years. ${ }^{3}$ Older patients commonly present with a reduced ability to perform activities of daily living, multiple comorbid diseases, declining organ function, and reduced cognitive function. Given the increased toxicity of chemotherapy among the older adult population, the recommended therapeutic regimens (monotherapy or platinum-based combination therapy) used to treat lung cancer in this population varies in different countries. Patients with epidermal growth factor receptor (EGFR)-mutated NSCLC have been reported to display a higher response rate and longer progression-free survival (PFS) when treated with $E G F R$ tyrosine kinase inhibitors (TKIs) compared with conventional chemotherapy. ${ }^{4-6}$ Several studies have reported that EGFR-TKIs produce favorable outcomes and acceptable toxicity levels among older patients with EGFRmutated advanced NSCLC. ${ }^{7-11}$

Available safety and efficacy data regarding anti-cancer treatments in lung cancer patients with Eastern Cooperative Oncology Group (ECOG) performance status (PS) of 2-4 are quite limited because this population has been universally excluded from large clinical trials. However, patients with poor PS (2-4) comprise $34-48 \%$ of all lung cancer patients at the time of initial diagnosis. ${ }^{12}$ A recent study reported that the lung cancer survival rate increased significantly following the launch of gefitinib and erlotinib in Taiwan. ${ }^{13}$ However, whether the improved outcomes, including the response rate, PFS, and OS, reported for EGFR-TKI treatment can be observed among older patients with poor PS remains unknown. The aim of this study was to examine the efficacy and prognosis of various EGFR-TKIs as first-line treatments for $E G F R$-mutated NSCLC in patients 65 years and older, including those with poor PS of $2-4$. The associated factors that impact the outcomes in this population were also analyzed.

\section{Materials and Methods}

\section{Patient Selection and Data Collection}

This study was performed as a multicenter, retrospective study of a single medical center and 3 regional hospitals in Taiwan. Between January 2015 and December 2019, patients who fulfilled all of the following criteria were eligible for the study: 1) Diagnosed with locally advanced or metastatic (Stage IIIb/IIIc/IV) NSCLC who were confirmed as positive for sensitizing EGFR mutation; 2) EGFR-TKI administered as the first-line treatment; and 3) aged $\geq 65$ years at the time of EGFR-TKI treatment initiation. Patients were excluded from the study if they were involved in any clinical trials or received combination treatment, including chemotherapeutic drugs, antiangiogenesis drugs, or radiotherapy. Patients who were switched to another EGFR-TKI drug during treatment were excluded from efficacy and prognosis analyses. The study was approved by the Institutional Review Boards of all participating hospitals.

The type of EGFR-TKI therapy, including $250 \mathrm{mg}$ of gefitinib (Iressa ${ }^{\circledR}$, AstraZeneca, Cambridge, England), 150 $\mathrm{mg}$ of erlotinib (Tarceva ${ }^{\circledR}$, Hoffmann-La Roche, Basel Switzerland), and $40 \mathrm{mg}$ or $30 \mathrm{mg}$ of afatinib (Giotrif ${ }^{\mathbb{R}}$, Boehringer Ingelheim, Ingelheim, Germany), was recorded at baseline under real-world settings. Demographic and clinical data related to lung cancer were collected, including age, sex, smoking status, cancer staging at diagnosis, metastatic site, EGFR mutation subtype, ECOG PS score, and comorbid diseases at baseline.

\section{Statistical Analysis}

Efficacy and prognosis analyses were conducted for all patients who received afatinib, erlotinib, or gefitinib as first-line treatment. Continuous variables with non-normal distributions are expressed as the median (range), whereas categorical variables are expressed as the frequency (percentage). The Kruskal-Wallis analysis was used to compare continuous variables among different groups. The Chi-square test and Fisher's exact test were used to compare response rates among different subgroups. The median time to PFS and OS were calculated using the KaplanMeier method. Subgroup analyses for the objective response rate were implemented according to ECOG PS score, age, and TKI treatment. Univariate Cox regression analyses were applied to evaluate the effects of clinical factors on the prognosis of lung cancer patients treated with EGFR-TKIs. All statistical analyses were performed using SPSS 25.0 and R 3.6.0 software. Significance was accepted at $\mathrm{p}<0.05$.

\section{Results}

A total of 237 patients with NSCLC were screened and enrolled in this study. Of these patients, 32 were excluded due to switching to another TKI drug or missing data, resulting in a total of 205 patients being included in endpoint analyses. Among those patients, 51 (26.0\%) were 
still living at the data collection cutoff point of December 31,2020 . The demographic characteristics of the studied population are presented in Table 1. The median age was 77 years, ranging from 65 to 95 years. The proportions of patients with PS scores of $0-1$ and $2-4$ were $55.6 \%$ and $44.4 \%$, respectively. A large proportion of the patients were women $(59.5 \%)$, and most were never-smokers $(70.2 \%)$, followed by former $(16.1 \%)$ and current smokers

Table I Demographic Information and Baseline Characteristics of the Patients Included in This Study

\begin{tabular}{|c|c|c|c|}
\hline Characteristics & \multicolumn{3}{|c|}{ Population $(n=205)$} \\
\hline Age (years), median (range) & & & 77 (49-95) \\
\hline Age group (years) & & $\begin{array}{l}65-75 \\
75-85 \\
\geq 85\end{array}$ & $\begin{array}{l}91(44.6 \%) \\
91(44.6 \%) \\
23(10.8 \%)\end{array}$ \\
\hline Sex & & $\begin{array}{l}\text { Female } \\
\text { Male }\end{array}$ & $\begin{array}{l}122(59.5 \%) \\
83(40.5 \%)\end{array}$ \\
\hline ECOG Performance Status & & $\begin{array}{l}0-1 \\
2-4\end{array}$ & $\begin{array}{l}\text { II } 4 \text { (55.6\%) } \\
9 \text { I (44.4\%) }\end{array}$ \\
\hline Smoking status & & $\begin{array}{l}\text { Nonsmoker } \\
\text { Current smoker } \\
\text { Ex-smoker }\end{array}$ & $\begin{array}{l}144(70.2 \%) \\
28(13.7 \%) \\
33(16.1 \%)\end{array}$ \\
\hline Comorbidities & & $\begin{array}{l}0 \\
1 \\
2 \\
3\end{array}$ & $\begin{array}{l}75(36.6 \%) \\
114(55.6 \%) \\
11(5.4 \%) \\
5(2.4 \%)\end{array}$ \\
\hline Metastatic Sites & & $\begin{array}{l}<3 \\
\geq 3\end{array}$ & $\begin{array}{l}133(64.9 \%) \\
72(35.1 \%)\end{array}$ \\
\hline Bone metastasis & & $\begin{array}{l}\text { No } \\
\text { Yes }\end{array}$ & $\begin{array}{l}119(58 \%) \\
86(42 \%)\end{array}$ \\
\hline Lung metastasis & & $\begin{array}{l}\text { No } \\
\text { Yes }\end{array}$ & $\begin{array}{l}125(61 \%) \\
80(39 \%)\end{array}$ \\
\hline Malignant effusion & & $\begin{array}{l}\text { No } \\
\text { Yes }\end{array}$ & $\begin{array}{l}127(62 \%) \\
78(38 \%)\end{array}$ \\
\hline Brain metastasis & & $\begin{array}{l}\text { No } \\
\text { Yes }\end{array}$ & $\begin{array}{l}138 \text { (67.3\%) } \\
67(32.7 \%)\end{array}$ \\
\hline Liver metastasis & & $\begin{array}{l}\text { No } \\
\text { Yes }\end{array}$ & $\begin{array}{l}188(91.7 \%) \\
17(8.3 \%)\end{array}$ \\
\hline Other metastases & & $\begin{array}{l}\text { No } \\
\text { Yes }\end{array}$ & $\begin{array}{l}181 \text { (88.3\%) } \\
24 \text { (1I.7\%) }\end{array}$ \\
\hline Initial TKI & $\begin{array}{l}\text { Ist generation } \\
\text { 2nd generation }\end{array}$ & $\begin{array}{l}\text { Gefitinib } \\
\text { Erlotinib } \\
\text { Afatinib } 40 \mathrm{mg} \\
\text { Afatinib } 30 \mathrm{mg}\end{array}$ & $\begin{array}{l}95(46.3 \%) \\
38(18.5 \%) \\
36(17.6 \%) \\
36(17.6 \%)\end{array}$ \\
\hline Adverse Event & & $\begin{array}{l}\text { No } \\
\text { Yes }\end{array}$ & $\begin{array}{l}55(26.8 \%) \\
150(73.2 \%)\end{array}$ \\
\hline Status & & $\begin{array}{l}\text { Living } \\
\text { Dead }\end{array}$ & $\begin{array}{l}51 \text { ( } 26.0 \%) \\
\text { I } 45(74.0 \%)\end{array}$ \\
\hline
\end{tabular}

Abbreviations: ECOG, Eastern Cooperative Oncology Group; TKI, tyrosine kinase inhibitor. 
(13.7\%). Most patients were initially diagnosed at Stage IV $(95.6 \%)$, with $<3$ metastatic sites $(64.9 \%)$. The most common metastatic sites were bone (42.0\%), lung $(39.0 \%)$, pleural effusion $(38.0 \%)$, brain $(32.7 \%)$, and liver $(8.3 \%)$. When treatment was analyzed, $46.3 \%$, $18.5 \%, 17.6 \%$, and $17.6 \%$ of patients were treated with $250 \mathrm{mg}$ gefitinib, $150 \mathrm{mg}$ erlotinib, $40 \mathrm{mg}$ afatinib, and 30 mg afatinib, respectively. The median PFS and OS of the included patients were 13.6 and 26.0 months, respectively.

Table 2 summarizes the baseline characteristics of patients according to ECOG PS scores. Compared with patients classified as good PS (0-1), those with poor PS were older (79 versus 75 years, $\mathrm{p}<0.001$ ), had a higher proportion of brain metastases $(41.8 \%$ versus $25.4 \%, \mathrm{p}=$ 0.013 ), were more likely to present with comorbidities (74.7\% versus $54.4 \%, p=0.008)$, and were more likely to receive first-generation TKIs $(74.7 \%$ versus $57.0 \%, \mathrm{p}=$ 0.026). Among patients with PS of $0-1$, the PFS and OS were longer than those with PS of 2-4 (PFS: 17.1 versus 12.7 months, $\mathrm{p}<0.001$; OS: 26.7 versus 18.2 months, $\mathrm{p}<$ 0.001 ; Figure 1). When sorted by patient subgroups, as shown in Table 3, older patients were associated with a higher portion of Stage III disease $(\mathrm{p}=0.012)$ and poorer PS $(\mathrm{p}<0.001)$ but fewer bone metastases $(\mathrm{p}=0.030)$. Figure 2 illustrates that older patients were associated with significantly worse $\operatorname{OS}(27.3,20.1$, and 14.1 months [p = 0.015 ] in patients aged 65 to $<75$ years, 75 to $<85$ years, and $\geq 85$ years, respectively) but not with significantly worse PFS $(17.6,14.2$, and 11.9 months $[p=0.100]$ in patients aged 65 to $<75$ years, 75 to $<85$ years, and $\geq 85$ years, respectively). As shown in Table 4, patients treated with afatinib were relatively younger $(\mathrm{p}=0.056)$, had better PS scores $(p=0.026)$, fewer liver metastases $(p=$ 0.002 ), and were associated with significantly better PFS (13.7, 13.2, and 21.4 months in patients treated with gefitinib, erlotinib, and afatinib [ $\mathrm{p}<0.001]$, respectively), but not for OS $(20.2,20.0$, and 29.0 months in patients treated with gefitinib, erlotinib, and afatinib $[p=0.086]$, respectively; Figure 3).

In the subgroup survival analysis, significant differences were identified between patients with and without brain metastases at diagnosis, with PFS of 12.2 and 16.2 months $(\mathrm{p}=0.033)$ and OS of 17.7 and 26.7 months $(\mathrm{p}=$ 0.0023 ), respectively (Figure 4). Figure 5 shows that patients with $\geq 3$ metastatic sites, compared with those with $<3$ metastatic sites, were associated with shorter PFS (13.2 versus 17.1 months, $\mathrm{p}=0.027$ ) and OS (17.7 versus 27.8 months, $\mathrm{p}=0.008)$. There were no significant differences of PFS $(p=0.067)$ or OS $(p=0.13)$ between patients with or without liver metastases (Figure S1).

In the multivariable survival analysis, a good ECOG PS of $0-1$, afatinib as the first-line treatment, and $<3$ metastatic sites at diagnosis were significantly associated with longer PFS. Relatively younger age, a good ECOG PS, $<3$ metastatic sites, and no brain metastasis at diagnosis were associated with better OS (Figure 6).

\section{Discussion}

In this multicenter, retrospective study, we examined the efficacy of first-line EGFR-TKI treatment for older $(\geq 65$ years) patients with poor ECOG PS in Taiwan. Our study indicated that patients with poor ECOG PS tended to be older, were more likely to present with brain metastases and comorbidities, and were more likely to receive firstgeneration TKIs compared to those with good ECOG PS. A good PS and $<3$ metastatic sites in this population were associated with better PFS and OS. Use of afatinib as the first-line treatment rather than gefitinib or erlotinib were associated with longer PFS, whereas a younger age in the elderly and no brain metastasis at diagnosis were associated with longer OS.

Compared with conventional chemotherapy, EGFR-TKI therapy was associated with a higher response rate, better symptom control, and quality of life improvements among patients with advanced EGFR-mutated NSCLC. ${ }^{14-17}$ However, older patients are frequently undertreated due to the expectation these will present with poor tolerance for treatment. ${ }^{18}$ The use of standard treatment protocols, including chemotherapy and targeted therapy, is recommended for patients with good PS, regardless of age. ${ }^{19}$ Previous studies have demonstrated that efficacy and tolerance of EGFR-TKI were comparable between older patients and the general population among those with EGFR-mutated NSCLC. ${ }^{10}$ Some studies have indicated that older patients exhibited higher EGFR-TKI response rates and longer OS than the general population. $^{20,21}$ The current study using a realworld setting, found the median PFS and OS among older patients were 13.6 and 26.0 months, which was comparable to previously reported studies in the general population. ${ }^{22}$ Nevertheless, the relatively older patients still tended to have poorer PS and were associated with worse OS.

Although conventional chemotherapy is not recommended for lung cancer patients with poor PS, modern anti-cancer treatments, including immunotherapies and targeted therapies, are relatively convenient and less toxic than chemotherapy. Although those treatments had been 
Table 2 Subgroup Analysis of Different ECOG PS Groups

\begin{tabular}{|c|c|c|c|c|}
\hline \multirow[t]{2}{*}{ Characteristics } & \multicolumn{3}{|c|}{ ECOG PS } & \multirow[t]{2}{*}{$P$-value } \\
\hline & $\begin{array}{c}0-1 \\
(n=114)\end{array}$ & $\begin{array}{c}2-4 \\
(n=91)\end{array}$ & $\begin{array}{c}\text { All } \\
(n=205)\end{array}$ & \\
\hline Age (years), median (range) & $75(65-90)$ & $79(65-95)$ & $77(65-95)$ & $<0.001$ \\
\hline Age (years) & & & & $<0.001$ \\
\hline $65-75$ & $64(56.1 \%)$ & 27 (29.7\%) & 91 (44.6\%) & \\
\hline $75-85$ & 44 (38.6\%) & 47 (5I.6\%) & 91 (44.6\%) & \\
\hline$\geq 85$ & $6(5.3 \%)$ & $17(18.7 \%)$ & $23(10.8 \%)$ & \\
\hline Sex & & & & 0.078 \\
\hline Female & 74 (64.9\%) & 48 (52.7\%) & 122 (59.5\%) & \\
\hline Male & $40(35.1 \%)$ & 43 (47.3\%) & 83 (40.5\%) & \\
\hline Initial Stage & & & & 0.081 \\
\hline Stage IIIB or IIIC & $2(1.8 \%)$ & $7(7.7 \%)$ & $9(4.4 \%)$ & \\
\hline Stage IV & II (98.2\%) & $84(92.3 \%)$ & $196(95.6 \%)$ & \\
\hline Smoking status & & & & 0.299 \\
\hline Nonsmoker & 85 (74.6\%) & 59 (64.8\%) & I 44 (70.2\%) & \\
\hline Current smoker & $14(12.3 \%)$ & 14 (I5.4\%) & $28(13.7 \%)$ & \\
\hline Ex-smoker & 15 (I3.2\%) & 18 (19.8\%) & $33(16.1 \%)$ & \\
\hline Comorbidities & & & & 0.008 \\
\hline 0 & $52(45.6 \%)$ & $23(25.3 \%)$ & 75 (36.6\%) & \\
\hline 1 & $53(46.5 \%)$ & 61 (67.0\%) & II 4 (55.6\%) & \\
\hline 2 & $5(4.4 \%)$ & $6(6.6 \%)$ & II (5.4\%) & \\
\hline 3 & $4(3.5 \%)$ & I (I.I\%) & $5(2.4 \%)$ & \\
\hline Metastatic Sites & & & & 0.243 \\
\hline$<3$ & $70(61.4 \%)$ & $63(69.2 \%)$ & 133 (64.9\%) & \\
\hline$\geq 3$ & 44 (38.6\%) & $28(30.8 \%)$ & $72(35.1 \%)$ & \\
\hline Bone metastasis & & & & 0.276 \\
\hline No & 70 (6I.4\%) & 49 (53.8\%) & 119 (58\%) & \\
\hline Yes & 44 (38.6\%) & $42(46.2 \%)$ & $86(42 \%)$ & \\
\hline Lung metastasis & & & & 0.311 \\
\hline No & 66 (57.9\%) & 59 (64.8\%) & $125(6 \mid \%)$ & \\
\hline Yes & 48 (42.1\%) & $32(35.2 \%)$ & 80 (39\%) & \\
\hline Malignant effusion & & & & 0.447 \\
\hline No & 68 (59.6\%) & 59 (64.8\%) & 127 (62\%) & \\
\hline Yes & 46 (40.4\%) & $32(35.2 \%)$ & 78 (38\%) & \\
\hline Brain metastasis & & & & 0.013 \\
\hline No & 85 (74.6\%) & 53 (58.2\%) & I38 (67.3\%) & \\
\hline Yes & 29 (25.4\%) & 38 (4I.8\%) & 67 (32.7\%) & \\
\hline Liver metastasis & & & & 0.431 \\
\hline No & 103 (90.4\%) & 85 (93.4\%) & 188 (91.7\%) & \\
\hline Yes & II (9.6\%) & $6(6.6 \%)$ & 17 (8.3\%) & \\
\hline Other metastasis & & & & 0.143 \\
\hline No & 104 (91.2\%) & 77 (84.6\%) & I8I (88.3\%) & \\
\hline Yes & $10(8.8 \%)$ & 14 (I5.4\%) & 24 (11.7\%) & \\
\hline
\end{tabular}


Table 2 (Continued).

\begin{tabular}{|c|c|c|c|c|}
\hline \multirow[t]{2}{*}{ Characteristics } & \multicolumn{3}{|c|}{ ECOG PS } & \multirow[t]{2}{*}{$P$-value } \\
\hline & $\begin{array}{c}0-1 \\
(n=I I 4)\end{array}$ & $\begin{array}{c}2-4 \\
(n=91)\end{array}$ & $\begin{array}{c}\text { All } \\
(n=205)\end{array}$ & \\
\hline Initial TKI & & & & 0.026 \\
\hline Gefitinib & 45 (39.5\%) & $50(54.9 \%)$ & 95 (46.3\%) & \\
\hline Erlotinib & $20(17.5 \%)$ & 18 (19.8\%) & 38 (I8.5\%) & \\
\hline Afatinib & 49 (43\%) & $23(25.3 \%)$ & 72 (35.1\%) & \\
\hline Adverse Event & & & & 0.895 \\
\hline No & 3 I (27.2\%) & $24(26.4 \%)$ & 55 (26.8\%) & \\
\hline Yes & 83 (72.8\%) & 67 (73.6\%) & 150 (73.2\%) & \\
\hline Status & & & & 0.001 \\
\hline Living & $4 \mathrm{I}(36.0 \%)$ & $16(17.6 \%)$ & 57 (27.8\%) & \\
\hline Dead & 73 (64.0\%) & 75 (82.4\%) & I 48 (72.2\%) & \\
\hline
\end{tabular}

Abbreviations: ECOG, Eastern Cooperative Oncology Group; PS, performance status; TKI, tyrosine kinase inhibitor.

used in the clinical setting for cancer patients with poor PS, limited data are available regarding the treatment efficacy in NSCLC patients with poor PS. A recent cohort study and a previous meta-analysis indicated that among patients treated with immunotherapy, ECOG PS $\geq 2$ was associated with a poor prognosis. ${ }^{23,24}$ After multivariate analysis, our study showed that PS remained an important prognostic factor for PFS and OS among older patients treated with EGFR-TKIs.

More metastatic sites indicate a higher tumor burden and may reflect the aggressiveness and rapid growth of cancer cells, which might be associated with a poor prognosis. Oh et al reported that tumor burden and the number of metastatic sites are predictors of poor outcomes in patients with NSCLC. ${ }^{25}$ A similar study, reported by Park et al, also indicated that the number of metastatic sites serves as a predictive factor for poor response and survival among patients with EGFR-mutated NSCLC who receive gefitinib treatment. ${ }^{26}$ These findings were in concordance to our present study, which showed that $\geq 3$ metastatic sites at diagnosis was a strong prognostic factor for PFS and OS among older patients with NSCLC.

Approximately $20 \%$ of newly diagnosed patients with advanced NSCLC have brain metastases, which are often associated with more neurological symptoms, poor quality of life, and worse prognosis. ${ }^{27}$ Patients with NSCLC harboring $E G F R$ mutations are more likely to suffer from brain metastases compared with those without EGFR
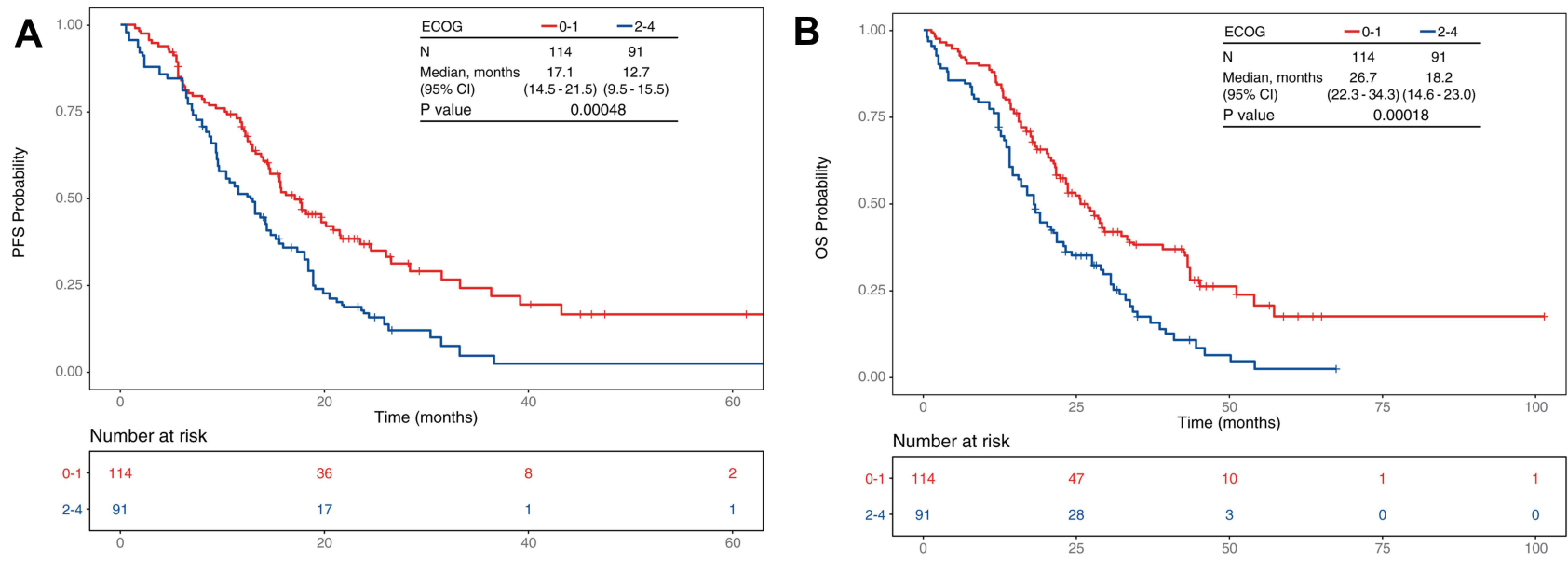

Figure I Kaplan-Meier plots in months of patients 65 years or older with EGFR-mutated Stage IIIB-IV NSCLC and receiving first-line EGFR-TKI treatment. Patients were grouped according to ECOG PS- $0-I$ (red, $N=114$ ) and 2-4 (blue, $N=91$ ). The number of patients at risk at $0,20,40$ and 60 months for each group are indicated in the table below the Kaplan-Meier plot. (A) PFS probability between different ECOG groups. (B) OS probability between different ECOG groups. 


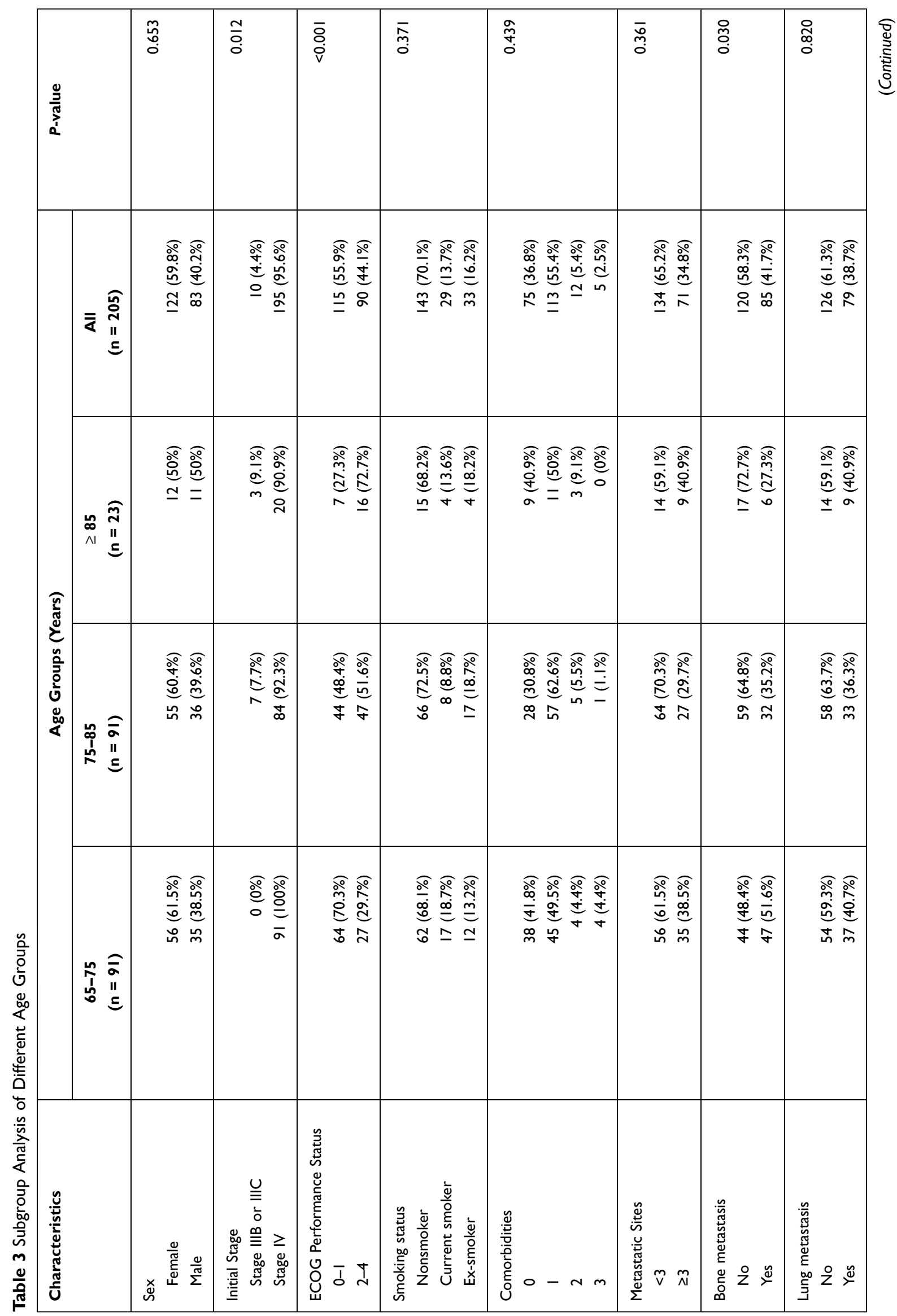




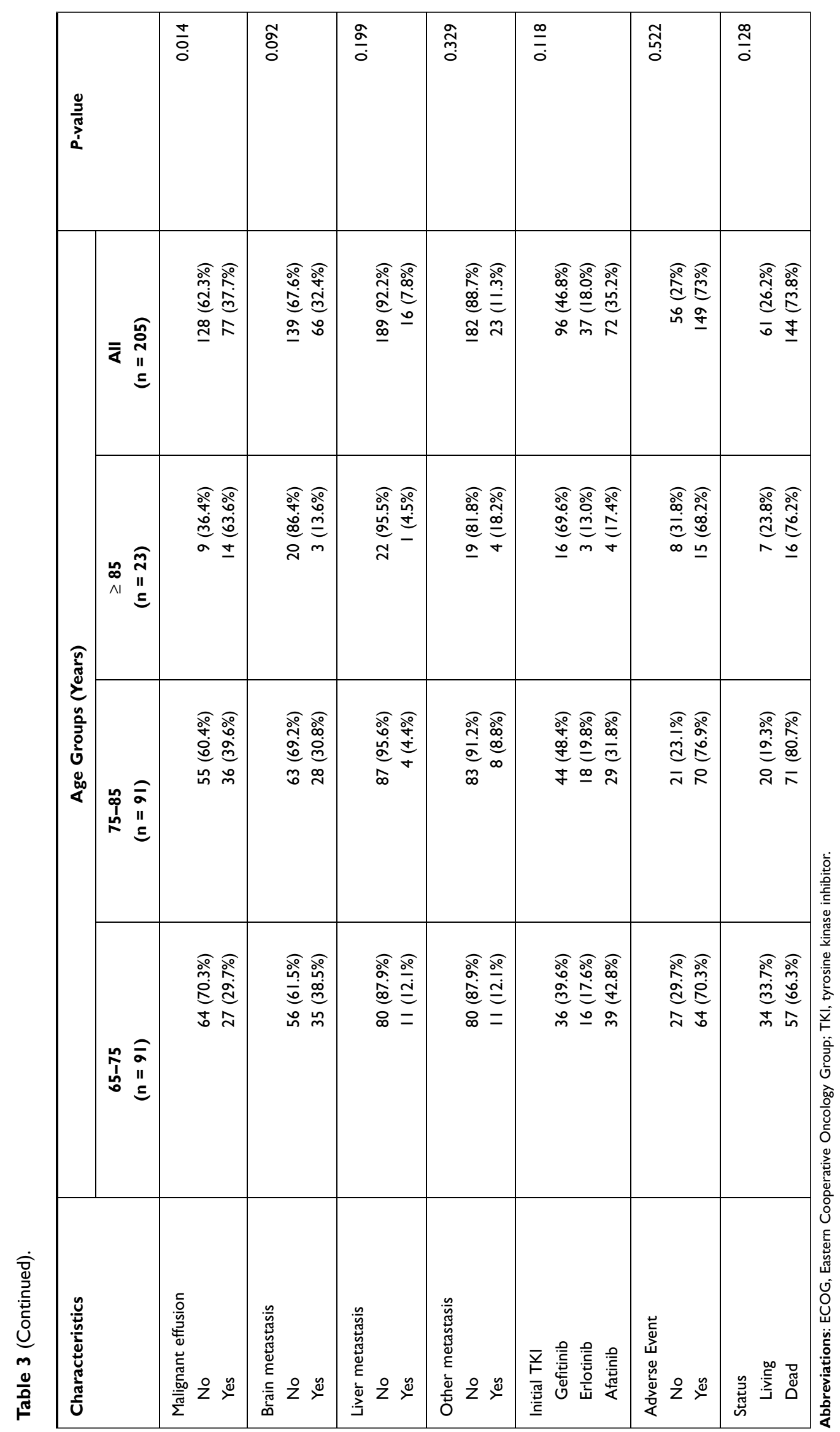



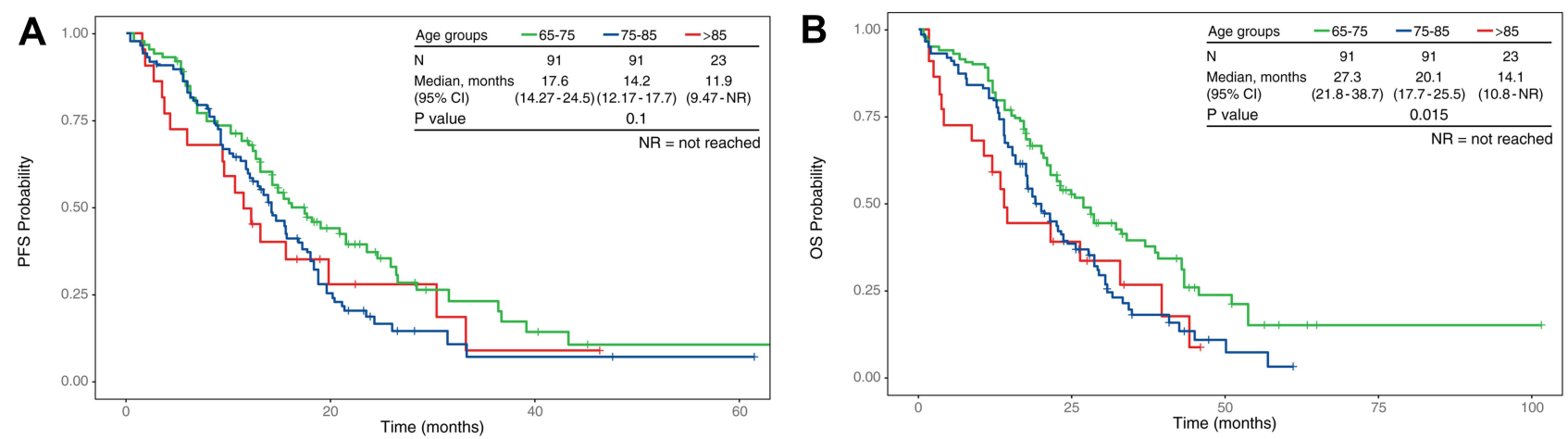

Figure 2 Kaplan-Meier plots in months of patients 65 years or older with EGFR-mutated Stage IIIB-IV NSCLC and receiving first-line EGFR-TKI treatment. Patients were grouped according to age group-65-75 (green, $N=91$ ), 75-85 (blue, $N=91$ ) and >85 (red, $N=23$ ). (A) PFS probability between different age groups. (B) OS probability between different age groups.

mutations. ${ }^{28}$ Although EGFR-TKIs demonstrate favorable intracranial responses in those patients with brain metastases, brain metastases have continued to be associated with a poor OS in previous studies. ${ }^{25,29,30}$ The subgroup analyses in the current study similarly indicated that the presence of brain metastases were marginally associated with shorter PFS and significantly associated with poor OS after multivariate analysis. Previous studies indicated liver metastasis was a significant poor prognostic factor in the EGFR-mutant patients, which was not observed in the current study, probably due to different population groups or relatively limited case numbers in this study. ${ }^{31,32}$

Another finding of current study indicated patients first-line treatment with afatinib, a second-generation EGFR-TKI, resulted in longer PFS as compared to those treated with erlotinib and gefitinib. Previous large studies demonstrated that afatinib significantly prolonged PFS compared to conventional chemotherapy (LUX-Lung 3 and LUX-Lung 6) or gefitinib (LUX-Lung 7), independent of age. ${ }^{10}$ Real-world studies also exhibited that afatinib has similar or even better efficacy compared with firstgeneration EGFR-TKIs across a broad range of patients in diverse clinical practice settings. ${ }^{30,33-35}$ One of these realworld data, similar to present study, implied afatinib was more likely to be used for younger patients in a better condition than other first-generation TKI inhibitors and observed a longer PFS and possible OS. ${ }^{34}$ In the current study, after adjusting for potential confounding factors such as age and ECOG-PS, first-line treatment with afatinib was still independently associated with a longer PFS.

Other EGFR-TKIs like osimertinib, a third-generation EGFR-TKI, was currently a preferred first-line treatment for advanced EGFR-mutated NSCLC patients. ${ }^{19}$ Treatment with osimertinib showed significant improvements in PFS and OS compared with gefitinib or erlotinib treatment, with a lower rate of serious adverse events. ${ }^{36}$ A retrospective study of 30 NSCLC patients with EGFR T790M mutation and poor PS of 2-4, demonstrated comparable efficacy and acceptable safety as previously studies. ${ }^{37}$ However, osimertinib may not be available or affordable in certain countries. Afatinib is likely the best alternative option as a first-line treatment in patients with limited access to osimertinib, to achieve the best PFS improvements.

The limitation of our study was that the use of a realworld, population-based setting resulted in imbalances when the study population was examined by different patient characteristics. For example, most of the older patients and patients with poor PS included in the current study were treated with gefitinib or erlotinib. In addition, the sample size was relatively small, which may also introduce bias and limit the possibility for general implications. Although the population of poor PS patients included in this study was relatively larger than those of previously reported studies, these findings require validation in future prospective, large-scale studies.

\section{Conclusion}

Our findings suggested that among older patients $(\geq 65$ years), those with EGFR-mutated and poor ECOG PS who receive EGFR-TKI treatment tended to be older, with a higher proportion of brain metastases, more comorbidities, and more likely to be treated with first-generation TKIs. A good PS of $0-1,<3$ metastatic sites, and the use of afatinib as first-line treatment rather than gefitinib or erlotinib, were associated with longer PFS among older patients. Relatively younger age, good PS, <3 metastatic sites, and no brain metastasis at diagnosis were associated 


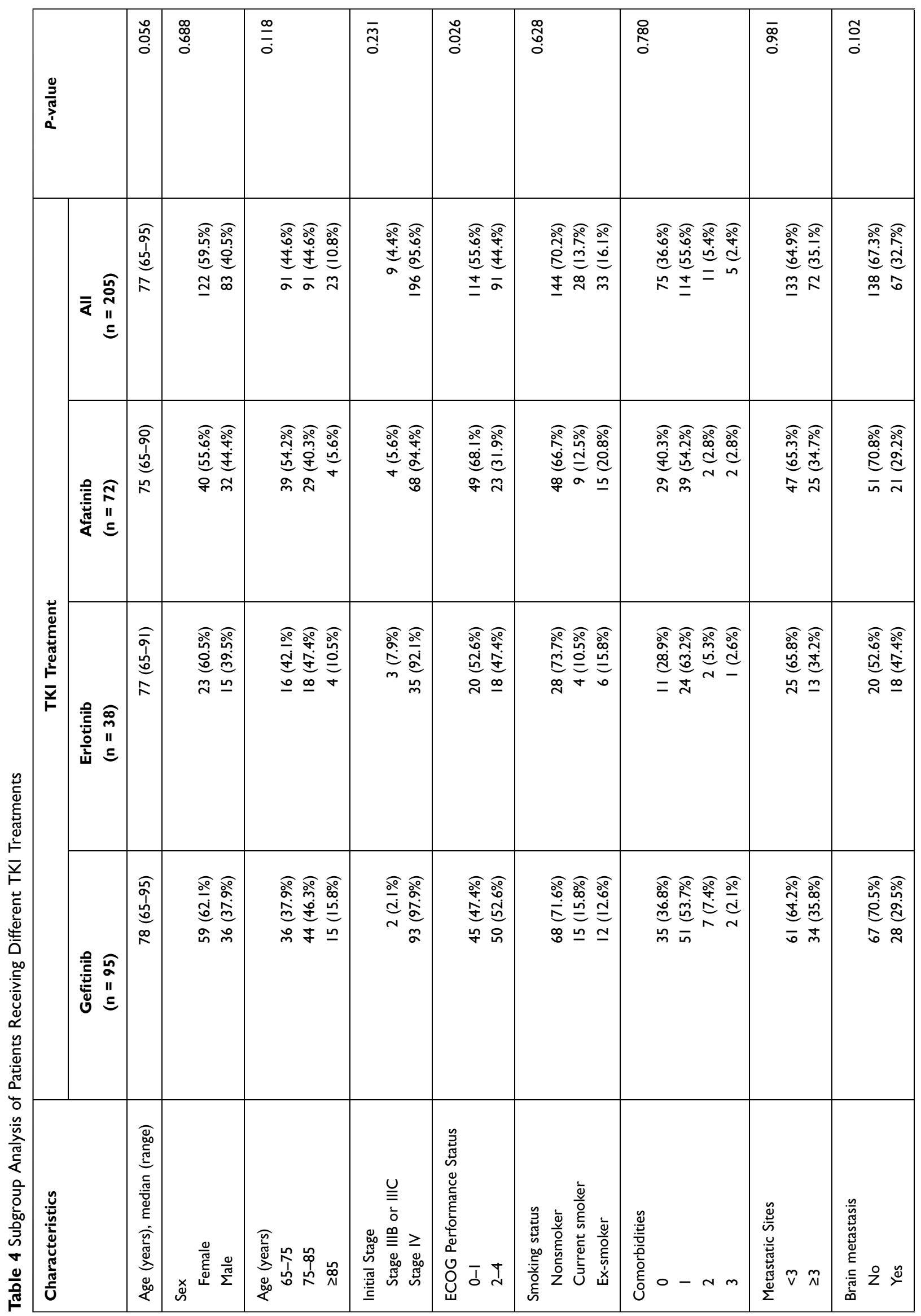




\begin{tabular}{|c|c|c|c|c|c|c|}
\hline ָָ ָ̃ & 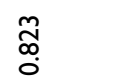 & $\begin{array}{l}\stackrel{R}{f} \\
\text { d }\end{array}$ & ర̊ & 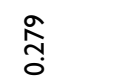 & $\stackrel{\stackrel{\circ}{\stackrel{\infty}{0}}}{0}$ & ્ָర \\
\hline 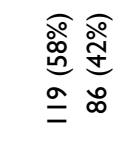 & 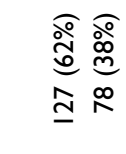 & 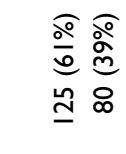 & 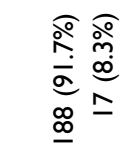 & 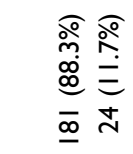 & 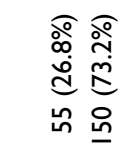 & 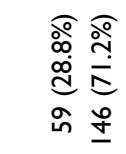 \\
\hline 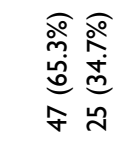 & 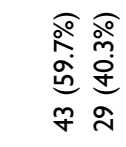 & 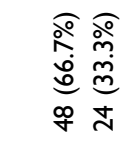 & 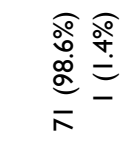 & 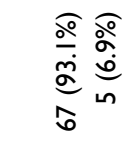 & 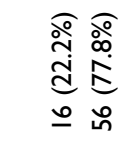 & 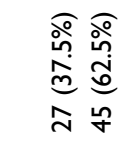 \\
\hline 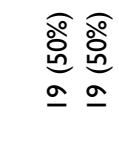 & 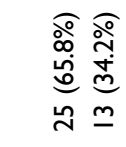 & 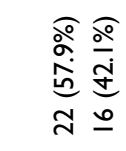 & 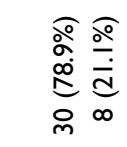 & 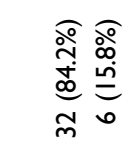 & 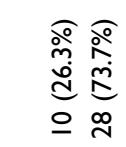 & 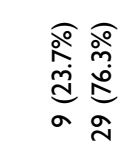 \\
\hline 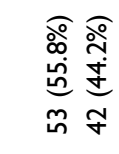 & 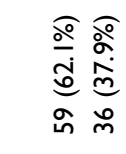 & 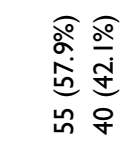 & 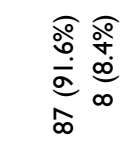 & 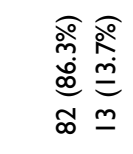 & 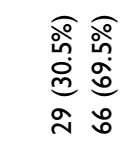 & 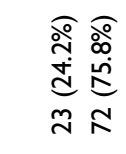 \\
\hline 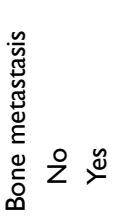 & 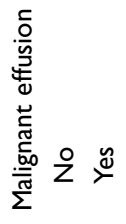 & 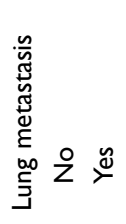 & 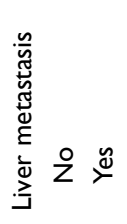 & 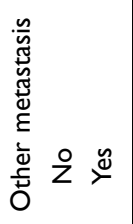 & 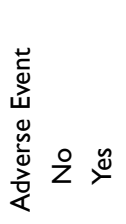 & 点 \\
\hline
\end{tabular}



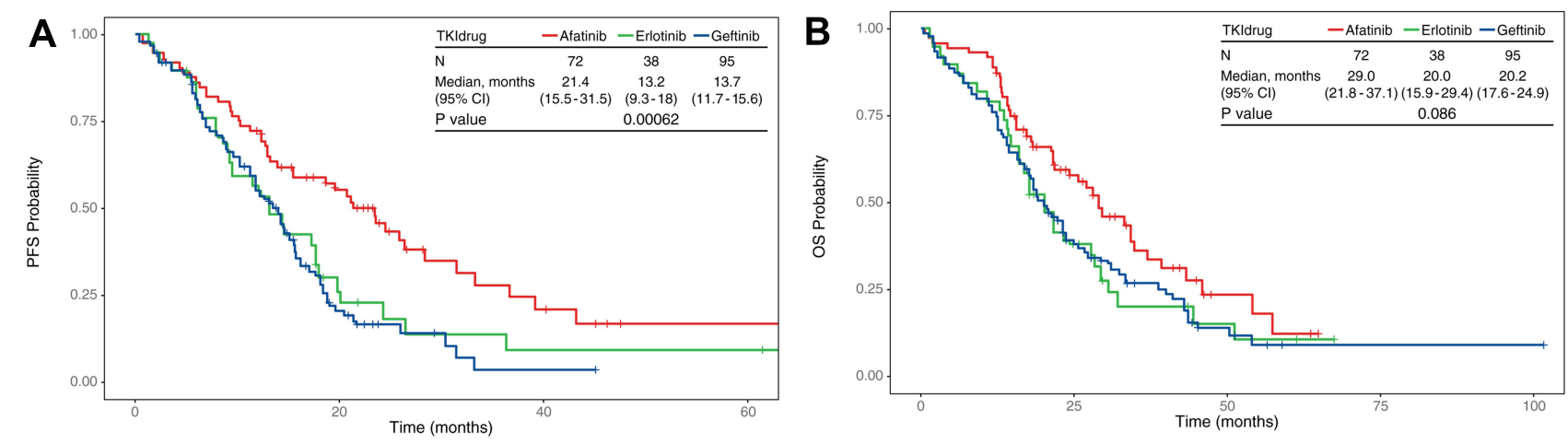

Figure 3 Kaplan-Meier plots in months of patients 65 years or older with EGFR-mutated Stage IIIB-IV NSCLC and receiving first-line EGFR-TKI treatment. Patients were grouped according to TKI drug treatment-afatinib (red, $N=72$ ), erlotinib (green, $N=38$ ) and gefitinib (blue, $N=95)$. (A) PFS probability between different TKI drug treatments. (B) OS probability between different TKI drug treatments.
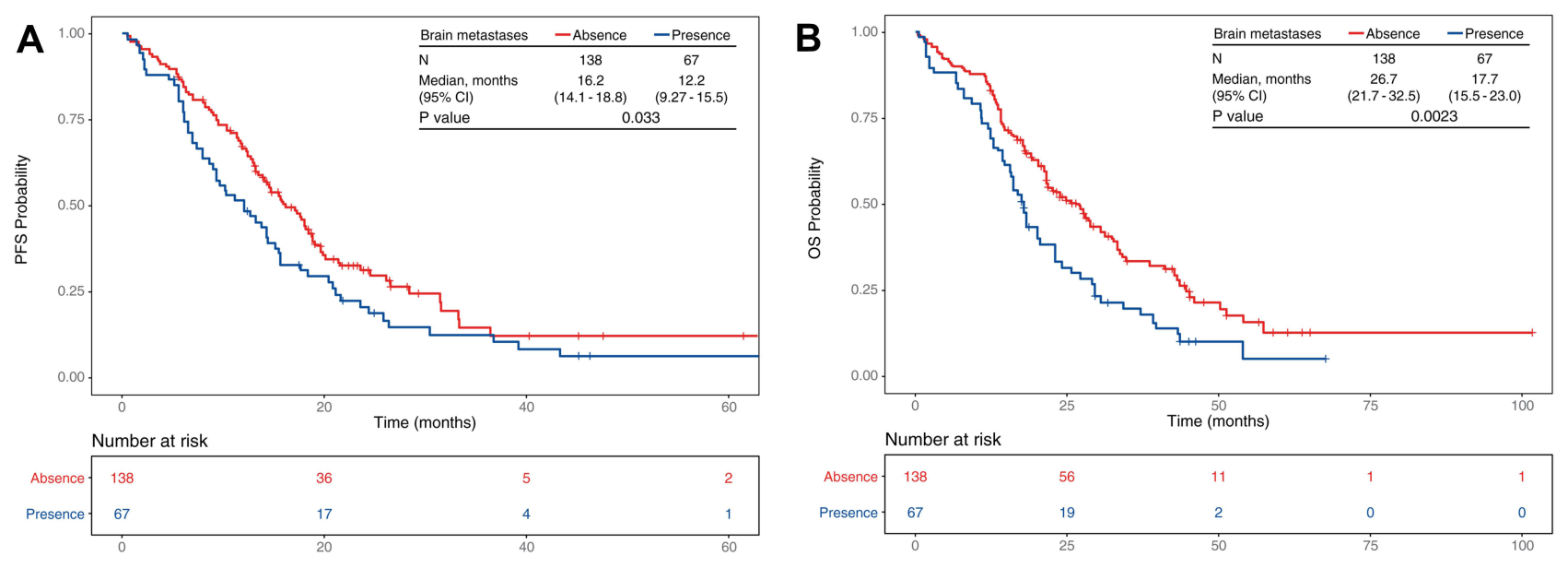

Figure 4 Kaplan-Meier plots in months of patients 65 years or older with EGFR-mutated Stage IIIB-IV NSCLC and receiving first-line EGFR-TKI treatment. Patients were grouped according to the absence or presence of brain metastases-absence (red, $N=138$ ) or presence (blue, $N=67$ ). The number of patients at risk at $0,20,40$ and 60 months for each group are indicated in the table below the Kaplan-Meier plot. (A) PFS probability between with or without brain metastasis. (B) OS probability with or without brain metastasis.
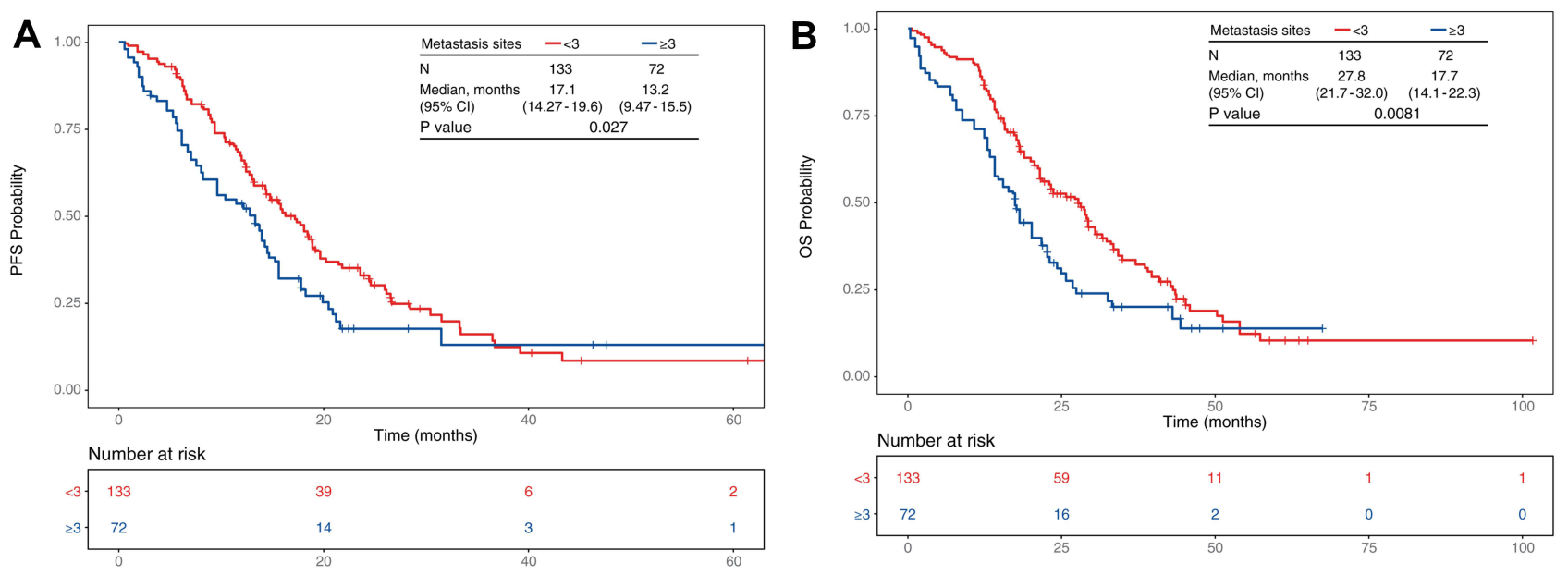

Figure 5 Kaplan-Meier plots of in months of patients 65 years or older with EGFR-mutated Stage IIIB-IV NSCLC and receiving first-line EGFR-TKI treatment. Patients were grouped according to the number of metastatic sites $-<3$ (red, $N=133$ ) or $\geq 3$ (blue, $N=72$ ). The number of patients at risk at $0,20,40$ and 60 months for each group are indicated in the table below the Kaplan-Meier plot. (A) PFS probability between patient groups with $<3$ or $\geq 3$ metastatic sites. (B) OS probability between patient groups with $<3$ or $\geq 3$ metastatic sites. 

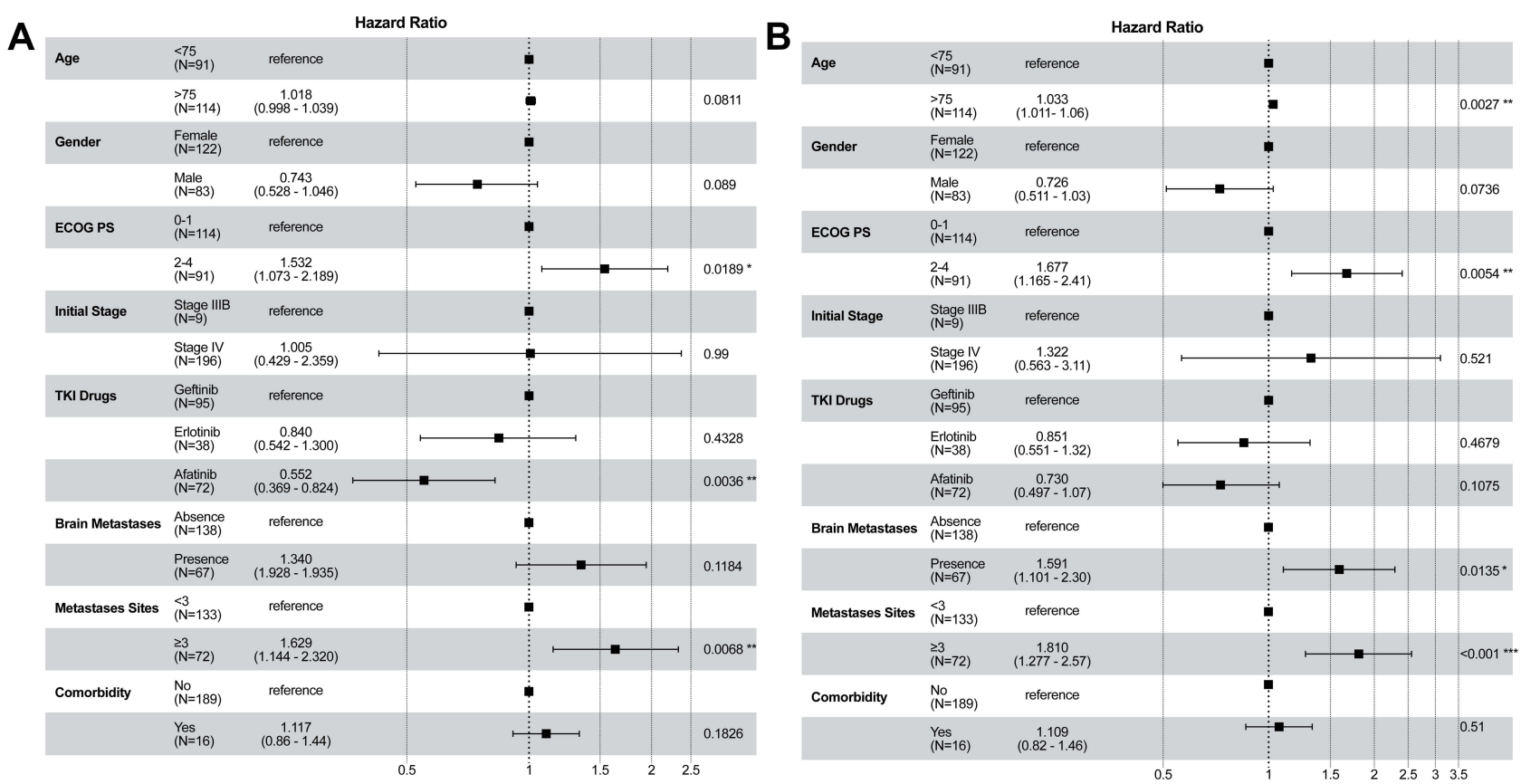

Figure 6 Forest plot of the multivariable survival analyses of patients 65 years or older with EGFR-mutated Stage IIIB-IV NSCLC and receiving first-line EGFR-TKI treatment. (A) PFS in different patient groups. (B) OS in different patient groups.

with better OS. These results may provide insights for the improved clinical care of older patients treated with EGFR-TKIs.

\section{Key Points}

- Whether the improved outcomes for EGFR-TKI treatment can be observed among older patients with EGFRmutated and poor PS remains unknown.

- Older patients with EGFR-mutated and poor ECOG PS were tended to be older, with a higher proportion of brain metastases, more comorbidities, and more likely to be treated with first-generation TKIs.

- Factors impact the outcomes in this population including a good PS, <3 metastatic sites, and the use of afatinib as first-line treatment rather than gefitinib or erlotinib, were associated with longer PFS among older patients. Relatively younger age, good PS, <3 metastatic sites, and no brain metastasis at diagnosis were associated with better OS.

\section{Ethical Approval}

The research was conducted in accordance with the approval by the Institutional Review Board (IRB) of four participating hospitals (E-Da Hospital EMRP-109-02, National Taiwan University Hospital NTUH-201611059RINB, Far Eastern Memorial Hospital FEMH-109162-F, and Yang-Ming
Chiao Tung University Hospital YMUH-2020A018, respectively), and waived the need to obtain consent for the collection, analysis and publication of the retrospectively obtained and anonymized data for this non-interventional study with the Declaration of Helsinki.

\section{Acknowledgments}

This study was supported by research grants from E-Da Hospital (EDAHP107022).

\section{Disclosure}

All authors have no conflicts of interest to disclose.

\section{References}

1. Sung H, Ferlay J, Siegel RL, et al. Global cancer statistics 2020: GLOBOCAN estimates of incidence and mortality worldwide for 36 cancers in 185 countries. CA Cancer J Clin. 2021;71(3):209-249. doi: $10.3322 /$ caac. 21660

2. Riessk J. Shifting paradigms in non-small cell lung cancer: an evolving therapeutic landscape. Am J Manag Care. 2013;19(19 Suppl): s390-397.

3. Wang BY, Huang JY, Cheng CY, Lin CH, Ko J, Liaw YP. Lung cancer and prognosis in Taiwan: a population-based cancer registry. $J$ Thorac Oncol. 2013;8(9):1128-1135. doi:10.1097/JTO.0b013e31829ceba4

4. Yang JC, Wu YL, Schuler M, et al. Afatinib versus cisplatin-based chemotherapy for EGFR mutation-positive lung adenocarcinoma (LUX-Lung 3 and LUX-Lung 6): analysis of overall survival data from two randomised, Phase 3 trials. Lancet Oncol. 2015;16(2):141151. doi:10.1016/S1470-2045(14)71173-8 
5. Mok TS, Wu YL, Thongprasert S, et al. Gefitinib or carboplatinpaclitaxel in pulmonary adenocarcinoma. $N$ Engl J Med. 2009;361 (10):947-957. doi:10.1056/NEJMoa0810699

6. Rosell R, Carcereny E, Gervais R, et al. Erlotinib versus standard chemotherapy as first-line treatment for European patients with advanced EGFR mutation-positive non-small-cell lung cancer (EURTAC): a multicentre, open-label, randomised phase 3 trial. Lancet Oncol. 2012;13(3):239-246. doi:10.1016/S1470-2045(11) 70393-X

7. Imai H, Kaira K, Suzuki K, et al. A Phase II study of afatinib treatment for elderly patients with previously untreated advanced non-small-cell lung cancer harboring EGFR mutations. Lung Cancer. 2018;126:41-47. doi:10.1016/j.lungcan.2018.10. 014

8. Asami K, Koizumi T, Hirai K, et al. Gefitinib as first-line treatment in elderly epidermal growth factor receptor-mutated patients with advanced lung adenocarcinoma: results of a Nagano lung cancer research group study. Clin Lung Cancer. 2011;12(6):387-392. doi:10.1016/j.cllc.2011.02.004

9. Passaro A, Alesini D, Pochesci A, Cortesi E. Erlotinib and gefitinib for elderly patients with advanced non-small-cell lung cancer. Anticancer Agents Med Chem. 2014;14(5):646-650. doi:10.2174/ 187152061405140501101624

10. Wu YL, Sequist LV, Tan EH, et al. Afatinib as first-line treatment of older patients with egfr mutation-positive non-small-cell lung cancer: subgroup analyses of the LUX-Lung 3, LUX-Lung 6, and LUX-Lung 7 trials. Clin Lung Cancer. 2018;19(4):e465-e479. doi:10.1016/j. cllc.2018.03.009

11. Maemondo M, Minegishi Y, Inoue A, et al. First-line gefitinib in patients aged 75 or older with advanced non-small cell lung cancer harboring epidermal growth factor receptor mutations: NEJ 003 study. $J$ Thorac Oncol. 2012;7(9):1417-1422. doi:10.1097/ JTO.0b013e318260de $8 \mathrm{~b}$

12. Lilenbaum RC, Cashy J, Hensing TA, Young S, Cella D. Prevalence of poor performance status in lung cancer patients: implications for research. $J$ Thorac Oncol. 2008;3(2):125-129. doi:10.1097/ JTO.0b013e3181622c17

13. Hsu JC, Wei CF, Yang SC, Lin PC, Lee YC, Lu CY. Lung cancer survival and mortality in Taiwan following the initial launch of targeted therapies: an interrupted time series study. BMJ Open. 2020;10(5):e033427. doi:10.1136/bmjopen-2019-033427

14. Geater SL, Xu CR, Zhou C, et al. Symptom and quality of life improvement in LUX-lung 6: an open-label phase III study of afatinib versus cisplatin/gemcitabine in asian patients with EGFR mutation-positive advanced non-small-cell lung cancer. J Thorac Oncol. 2015;10(6):883-889. doi:10.1097/JTO.0000000000000517

15. Yang JC, Hirsh V, Schuler M, et al. Symptom control and quality of life in LUX-Lung 3: a phase III study of afatinib or cisplatin/pemetrexed in patients with advanced lung adenocarcinoma with EGFR mutations. J Clin Oncol. 2013;31(27):3342-3350. doi:10.1200/ JCO.2012.46.1764

16. Chen G, Feng J, Zhou C, et al. Quality of life (QoL) analyses from OPTIMAL (CTONG-0802), a Phase III, randomised, open-label study of first-line erlotinib versus chemotherapy in patients with advanced EGFR mutation-positive non-small-cell lung cancer (NSCLC). Ann Oncol. 2013;24(6):1615-1622. doi:10.1093/annonc/ mdt012

17. Thongprasert S, Duffield E, Saijo N, et al. Health-related quality-oflife in a randomized phase III first-line study of gefitinib versus carboplatin/paclitaxel in clinically selected patients from Asia with advanced NSCLC (IPASS). J Thorac Oncol. 2011;6(11):1872-1880. doi:10.1097/JTO.0b013e31822adaf7

18. Beckett P, Callister M, Tata LJ, et al. Clinical management of older people with non-small cell lung cancer in England. Thorax. 2012;67 (9):836-839. doi:10.1136/thoraxjnl-2011-200994
19. Ettinger DS, Wood DE, Aisner DL, et al. NCCN guidelines insights: non-small cell lung cancer, version 2.2021. J Natl Compr Canc Netw. 2021;19(3):254-266. doi:10.6004/jnccn.2021.0013

20. Spigel DR, Lin M, O'Neill V, Hainsworth JD. Final survival and safety results from a multicenter, open-label, phase $3 \mathrm{~b}$ trial of erlotinib in patients with advanced nonsmall cell lung cancer. Cancer. 2008;112(12):2749-2755. doi:10.1002/cncr.23490

21. Thatcher N, Chang A, Parikh P, et al. Gefitinib plus best supportive care in previously treated patients with refractory advanced nonsmall-cell lung cancer: results from a randomised, placebo-controlled, multicentre study (Iressa survival evaluation in lung cancer). Lancet. 2005;366(9496):1527-1537. doi:10.1016/S0140-6736(05) 67625-8

22. Kim C, Liu SV. First-line EGFR TKI therapy in non-small-cell lung cancer: looking back before leaping forward. Ann Oncol. 2019;30 (12):1852-1855. doi:10.1093/annonc/mdz415

23. Sehgal K, Gill RR, Widick P, et al. Association of performance status with survival in patients with advanced non-small cell lung cancer treated with pembrolizumab monotherapy. JAMA Netw Open. 2021;4 (2):e2037120. doi:10.1001/jamanetworkopen.2020.37120

24. Dall'Olio FG, Maggio I, Massucci M, Mollica V, Fragomeno B, Ardizzoni A. ECOG performance status $>/=2$ as a prognostic factor in patients with advanced non small cell lung cancer treated with immune checkpoint inhibitors-A systematic review and meta-analysis of real world data. Lung Cancer. 2020;145:95-104. doi:10.1016/j. lungcan.2020.04.027

25. Oh Y, Taylor S, Bekele BN, et al. Number of metastatic sites is a strong predictor of survival in patients with nonsmall cell lung cancer with or without brain metastases. Cancer. 2009;115(13):2930-2938. doi:10.1002/cncr.24333

26. Park JH, Kim TM, Keam B, et al. Tumor burden is predictive of survival in patients with non-small-cell lung cancer and with activating epidermal growth factor receptor mutations who receive gefitinib. Clin Lung Cancer. 2013;14(4):383-389. doi:10.1016/j. cllc.2012.10.007

27. Proto C, Imbimbo M, Gallucci R, et al. Epidermal growth factor receptor tyrosine kinase inhibitors for the treatment of central nervous system metastases from non-small cell lung cancer: the present and the future. Transl Lung Cancer Res. 2016;5(6):563-578. doi:10.21037/tlcr.2016.10.16

28. Iuchi T, Shingyoji M, Itakura M, et al. Frequency of brain metastases in non-small-cell lung cancer, and their association with epidermal growth factor receptor mutations. Int J Clin Oncol. 2015;20(4):674679. doi:10.1007/s10147-014-0760-9

29. Chen YH, Chen YF, Chen CY, Shih JY, Yu CJ. Clinical factors associated with treatment outcomes in EGFR mutant non-small cell lung cancer patients with brain metastases: a case-control observational study. BMC Cancer. 2019;19(1):1006. doi:10.1186/s12885019-6140-0

30. Su PL, Wu YL, Chang WY, et al. Preventing and treating brain metastases with three first-line EGFR-tyrosine kinase inhibitors in patients with EGFR mutation-positive advanced non-small cell lung cancer. Ther Adv Med Oncol. 2018;10:1758835918797589. doi: $10.1177 / 1758835918797589$

31. Chang YP, Chen YM, Lai CH, et al. The impact of de novo liver metastasis on clinical outcome in patients with advanced non-smallcell lung cancer. PLoS One. 2017;12(6):e0178676. doi:10.1371/journal.pone. 0178676

32. Wu KL, Tsai MJ, Yang CJ, et al. Liver metastasis predicts poorer prognosis in stage IV lung adenocarcinoma patients receiving firstline gefitinib. Lung Cancer. 2015;88(2):187-194. doi:10.1016/j. lungcan.2015.02.012

33. Su VY, Yang KY, Huang TY, et al. The efficacy of first-line tyrosine kinase inhibitors combined with co-medications in Asian patients with EGFR mutation non-small cell lung cancer. Sci Rep. 2020;10 (1):14965. doi:10.1038/s41598-020-71583-w 
34. Hsieh YY, Fang WT, Lo YW, Chen YH, Chien LN. Comparing the effectiveness of different EGFR-TKIs in patients with EGFR mutant non-small-cell lung cancer: a retrospective cohort study in Taiwan. Int $J$ Cancer. 2020;147(4):1107-1116. doi:10.1002/ijc.32841

35. Chang CY, Lai YC, Wei YF, Chen CY, Chang SC. PD-L1 expression and outcome in patients with metastatic non-small cell lung cancer and EGFR mutations receiving EGFR-TKI as frontline treatment Onco Targets Ther. 2021;14:2301-2309. doi:10.2147/OTT.S290445
36. Soria JC, Ohe Y, Vansteenkiste J, et al. Osimertinib in untreated egfrmutated advanced non-small-cell lung cancer. $N$ Engl $J$ Med. 2018;378(2):113-125. doi:10.1056/NEJMoa1713137

37. Nakashima K, Kimura M, Akamatsu H, et al. Osimertinib for patients with EGFR T790M mutation-positive non-small-cell lung cancer and a poor performance status. Jpn J Clin Oncol. 2019;49(7):671-675. doi:10.1093/jjco/hyz041

\section{Publish your work in this journal}

Cancer Management and Research is an international, peer-reviewed open access journal focusing on cancer research and the optimal use of preventative and integrated treatment interventions to achieve improved outcomes, enhanced survival and quality of life for the cancer patient.
The manuscript management system is completely online and includes a very quick and fair peer-review system, which is all easy to use. Visit http://www.dovepress.com/testimonials.php to read real quotes from published authors. 